\title{
Sperm-epithelium relationships in relation to the time of insemination in little brown bats (Myotis lucifugus)
}

\author{
P. A. Racey*, T. A. Uchida $\uparrow$, T. Mōri†, M. I. Avery* and M. B. Fenton $\ddagger \S$ \\ ${ }^{*}$ Department of Zoology, University of Aberdeen, Aberdeen AB9 2TN, U.K., \\ $\dagger$ Zoological Laboratory, Faculty of Agriculture, Kyushu University, Fukuoka 812, Japan; and \\ $\ddagger$ Department of Biology, Carleton University, Ottawa, Canada K19 5B6
}

\begin{abstract}
Summary. Copulation lasted for up to $46 \mathrm{~min}$ in little brown bats. Spermatozoa were stored in both the uterus and the utero-tubal junction, although intimate relationships between spermatozoa and the epithelium were particularly evident in the utero-tubal junction, and were established at the beginning of the period of sperm storage. Polymorphonuclear leucocytes were present in all uteri irrespective of whether or not they had been inseminated but were not generally present in the utero-tubal junction or oviduct. Engulfment of spermatozoa by the epithelial cells of the utero-tubal junction and by polymorphonuclear leucocytes in the uterine glands was evident soon after copulation. It is suggested that this may effect the removal of defective spermatozoa and allow luminal spermatozoa access to the spatially restricted storage sites.

Uninseminated female bats attempted to elicit copulation from torpid males, and were also observed adjacent to copulating pairs. Female bats also uttered copulation calls.
\end{abstract}

\section{Introduction}

Wimsatt $(1942,1944)$ carried out the first experiments to establish the prolonged survival of spermatozoa in hibernating vespertilionid bats, by isolating female little brown bats (Myotis lucifugus) and big brown bats (Eptesicus fuscus) from males after insemination and observing developing embryos in the reproductive tract of bats after their arousal from hibernation in spring. Wimsatt et al. (1966) subsequently showed spermatozoa in close contact with the endometrium in little brown bats during the period of storage and Wimsatt (1969) referred to a specialized 'sperm receptable region' in the female reproductive tract of this species. This region has recently been identified as the utero-tubal junction and described by Krutzsch et al. (1982).

The existence of a hibernaculum for little brown bats, where sexual activity could be observed from its inception in early autumn and the bats involved captured (Thomas et al., 1979; Barclay et al., 1979), provided an opportunity to examine the relationship between spermatozoa and their storage organs in the female reproductive tract soon after insemination. The aim of this study was to correlate behavioural and morphological observations from the inception of copulation and to examine sperm-epithelial relationships in the female reproductive tract in relation to the time of mating.

\section{Materials and Methods}

Fieldwork was carried out from 19 August to 4 September 1982 at Renfrew mine, Renfrew county, Ontario (Fenton, 1970) and was timed to coincide with the onset of mating in late August (Thomas et al., 1979). Bats, entering or leaving the mine were caught in Tuttle traps (Tuttle, 1974) set on flight paths at the entrance to the mine. A single trap set at the mine entrance at dusk caught bats entering and leaving, but when 2 traps were set close together, the trap further from the mine caught only bats entering. Such an arrangement enabled us to distinguish between bats

§Present address: Department of Biology, York University, Downsview, Ontario, Canada M3J 1P3. 
arriving at the mine to mate, and those which had already been inside the mine, and may have mated. Samples of bats were killed by cervical dislocation, uteri were dissected and smear and squash preparations in normal saline $(9 \mathrm{~g} \mathrm{NaCl} / 1)$ were examined by phase-contrast microscopy to ascertain the incidence of insemination by 21 August. Similar samples at the end of the study were fixed in Bouin's fluid, embedded in paraffin wax, serially sectioned at 5-6 $\mu \mathrm{m}$ and stained with haematoxylin and eosin.

Each night the mine was patrolled 2 to 4 times (P.A.R. and M.I.A.) using head torches fitted with red filters, to search for copulating bats which often produce audible cries (Barclay \& Thomas, 1979; Barclay et al., 1979). Because even a stealthy approach generally disturbed bats copulating on the wall of the mine to flight, attempts were made to net copulating pairs as soon as they were located. Bats copulating in drill holes were less often disturbed and sometimes could be observed throughout copulation. These individuals were netted as they left the drill hole.

Captured females were held in cages for $10 \mathrm{~min}$ to $67 \mathrm{~h}$ and provided with water. They were then killed by cervical dislocation and a cannula was introduced into the thoracic aorta and sutured into position. The vena cava was then severed, and the bat perfused with about $20 \mathrm{ml}$ heparinized normal saline $(9 \mathrm{~g} \mathrm{NaCl} / \mathrm{l})$ to wash out the blood. This was immediately followed by about $20 \mathrm{ml} 2.5 \%$ glutaraldehyde and $0.5 \%$ paraformaldehyde buffered with $0.1 \mathrm{M}$ cacodylate buffer ( $\mathrm{pH}$ 7.4). Perfusion was successful in 21 female bats, but failed in 4, whereupon the uterus was incised and fixed by immersion. In one bat accidentally killed during capture, the reproductive tract was fixed in Bouin's fluid. After perfusion, the reproductive tracts were dissected out, freed of fat and excess connective tissue, immersed in fixative and mailed in vials to Japan. Pieces of the right uterine horn and utero-tubal junction were then post-fixed in $1.3 \%$ osmium, dehydrated in acetone and embedded in epoxy resin. Thick sections $(1.5 \mu \mathrm{m})$ cut with glass knives were mounted on glass slides, stained in $0.5 \%$ toluidine blue and observed with the aid of a light microscope. Thin sections $(\sim 60 \mathrm{~nm})$ were cut with a diamond knife, mounted on copper grids, stained with uranyl and lead citrate and examined in an Hitachi HS-9 Electron microscope $(75 \mathrm{kV})$.

Table 1. Occurrence of spermatozoa in the right uterine horn and oviduct of little brown bats

\begin{tabular}{|c|c|c|c|c|c|c|c|}
\hline \multirow[b]{3}{*}{$\begin{array}{l}\text { Bat } \\
\text { No. }\end{array}$} & \multirow[b]{3}{*}{ Status $\dagger$} & \multirow{3}{*}{$\begin{array}{c}\text { Capture to } \\
\text { fixation } \\
\text { interval }\end{array}$} & \multicolumn{5}{|c|}{ No. of spermatozoa and leucocytes (in parentheses) counted $\ddagger$ in: } \\
\hline & & & \multicolumn{2}{|c|}{ Uterus } & \multicolumn{2}{|c|}{ Utero-tubal junction } & \multirow[b]{2}{*}{$\begin{array}{l}\text { Caudal } \\
\text { isthmus }\end{array}$} \\
\hline & & & Lumen & Glands & $\begin{array}{l}\text { Colliculus } \\
\text { tubaricus }\end{array}$ & $\begin{array}{c}\text { Intramural } \\
\text { part }\end{array}$ & \\
\hline 11 & $\mathbf{U}$ & $5 \mathrm{~min}$ & $-(++)$ & $++(+)$ & - & - & - \\
\hline $23^{*}$ & $\mathrm{D}$ & $10 \mathrm{~min}$ & $+++(+)$ & $+++(+)$ & +++ & +++ & - \\
\hline $34^{*}$ & $\mathrm{U}$ & $15 \mathrm{~min}$ & $++t+(+)$ & $++t(t)$ & $+t+$ & $+t+$ & + \\
\hline 35 & $\mathrm{D}$ & $30 \mathrm{~min}$ & $+(+)$ & $++(+)$ & + & + & - \\
\hline 36 & $\mathrm{D}$ & $2 \mathrm{~h}$ & $-(++)$ & $-(+)$ & - & - & - \\
\hline 12 & $U$ & $12 \mathrm{~h}$ & $+(+)$ & $++(+)$ & + & + & - \\
\hline 1 & $\mathrm{D}$ & $12 \mathrm{~h}$ & $-(+)$ & $-(+)$ & - & - & - \\
\hline 13 & $\mathrm{O}$ & $13 \mathrm{~h}$ & $-(+)$ & $-(+)$ & - & - & - \\
\hline 5 & $\mathbf{U}$ & $14 \mathrm{~h}$ & $++(+)$ & $++(+)$ & + & + & - \\
\hline 2 & D & $15 \mathrm{~h}$ & $-(+)$ & $-(+)$ & - & - & - \\
\hline 9 & $\mathrm{D}$ & $15 \mathrm{~h}$ & $-(+)$ & $-(+)$ & - & - & - \\
\hline $14^{*}$ & $\mathrm{D}$ & $15 \mathrm{~h}$ & $+t+(t)$ & $++(+)$ & ++ & + & - \\
\hline 3 & $\mathrm{D}$ & $15 \mathrm{~h}$ & $++(++)$ & $++(+)$ & $+(+)$ & $+(+)$ & - \\
\hline 6 & $\mathrm{U}$ & $16 \mathrm{~h}$ & $-(+)$ & $-(t)$ & - & - & - \\
\hline 10 & $\mathrm{D}$ & $18 \mathrm{~h}$ & $++(+)$ & $++(+)$ & + & + & - \\
\hline 15 & $\mathrm{~S}$ & $30 \mathrm{~h}$ & $-(++)$ & $-(+)$ & - & - & - \\
\hline 4 & D & $36 \mathrm{~h}$ & $+(++)$ & $++(+)$ & $\S$ & $\S$ & $\S$ \\
\hline 8 & D & $37 \mathrm{~h}$ & $-(+)$ & $-(+)$ & - & - & - \\
\hline 16 & $\mathrm{D}$ & $60 \mathrm{~h}$ & $-(++)$ & $-(+)$ & - & - & - \\
\hline 17 & $\mathrm{D}$ & $60 \mathrm{~h}$ & $-(+)$ & $-(+)$ & - & - & - \\
\hline 18 & D & $60 \mathrm{~h}$ & $+(+)$ & $++(+)$ & - & - & - \\
\hline 19 & $\mathrm{O}$ & $63 \mathrm{~h}$ & $-(++)$ & $-(+)$ & - & - & - \\
\hline 21 & D & $66 \mathrm{~h}$ & $++(+)$ & $++(+)$ & + & - & - \\
\hline 22 & $\mathrm{O}$ & $66 \mathrm{~h}$ & $-(+)$ & $-(+)$ & - & - & - \\
\hline $20^{*}$ & D & $67 \mathrm{~h}$ & $++(++)$ & $++(+)$ & + & + & - \\
\hline
\end{tabular}

*Electron microscope observations.

$+\mathrm{D}=$ disturbed during coitus; $\mathrm{U}=$ undisturbed; $\mathrm{O}=$ onlooker; $\mathrm{S}=$ soliciting.

The symbols of,,,-++++++ and ++++ show $0,1-10,100-200,1000$ and 3000 spermatozoa/section, respectively; + and ++ each in parentheses indicates 1-20 and 21-100 polymorphonuclear leucocytes/section.

$\S$ Not possible to analyse.

No leucocytes were observed in the oviduct, with the exception of Bat 3 . 


\section{Results}

\section{Behavioural observations}

Copulation calls. These consist of a series of weak audible peeps easily distinguished from loud agonistic squawks. On one such occasion the attention of one of us (M.I.A.) was drawn to a group of 3 bats on the wall of the mine by a copulation call. All 3 bats were caught and consisted of 2 females jostling a torpid adult male. This suggests that the females are capable of making copulation calls, recognizing males in the darkness and attempting to elicit their sexual attention. On another occasion, copulation calls drew our attention to a drill hole where a pair of bats about $20 \mathrm{~cm}$ deep were in coitus. Copulation lasted for a further $46 \mathrm{~min}$; the male's back was arched and his teeth gripped the nape of the female whose mouth was frequently open. The male occasionally released the grip of his teeth to make a loud squawk. Throughout these episodes, copulation calls could still be heard, indicating that such calls were made by the female bat.

Duration of copulation. The reaction of bats to the observers was variable. Some pairs in coitus were apparently undisturbed when a net was placed over them. However the noise of approaching observers or the transitory illumination of a head torch was sufficient to cause the majority of pairs ( $n=16$ ) to disengage, and the females of the pairs, if caught, were recorded as disturbed in coitus. On one such occasion, a male in coitus attempted to fly but was prevented from doing so by his penis which was locked inside the vagina. On another, the female struggled to escape but the male repeatedly pulled her back with his forearms. On 4 occasions bats apparently disengaged spontaneously after they had been observed for $25,37,45$ and $46 \mathrm{~min}$. These pairs were then caught and in the first 3 cases the male had a massively engorged penis. In the last case the penis was not erect.

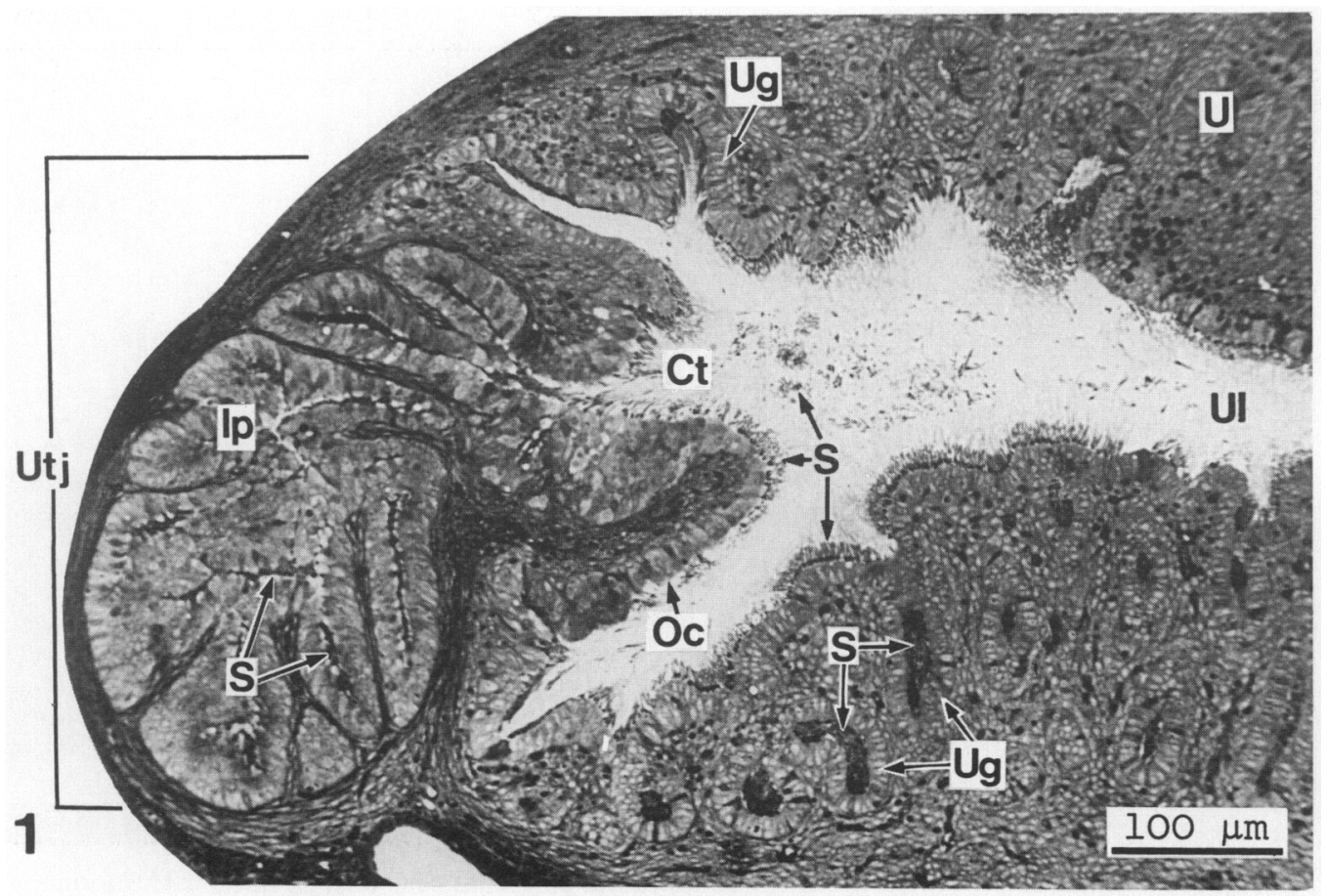

Fig. 1. Horizontal section through the right utero-tubal junction (UTJ) of Bat 34, showing the moderately developed colliculus tubaricus $(\mathrm{Ct})$ and the intramural part (Ip), in both of which many spermatozoa (S) are present as well as in the uterine lumen (Ul) and glands (Ug). Oc, outer wall of $\mathrm{Ct}$; $\mathrm{U}$, uterine wall. Toluidine blue. 

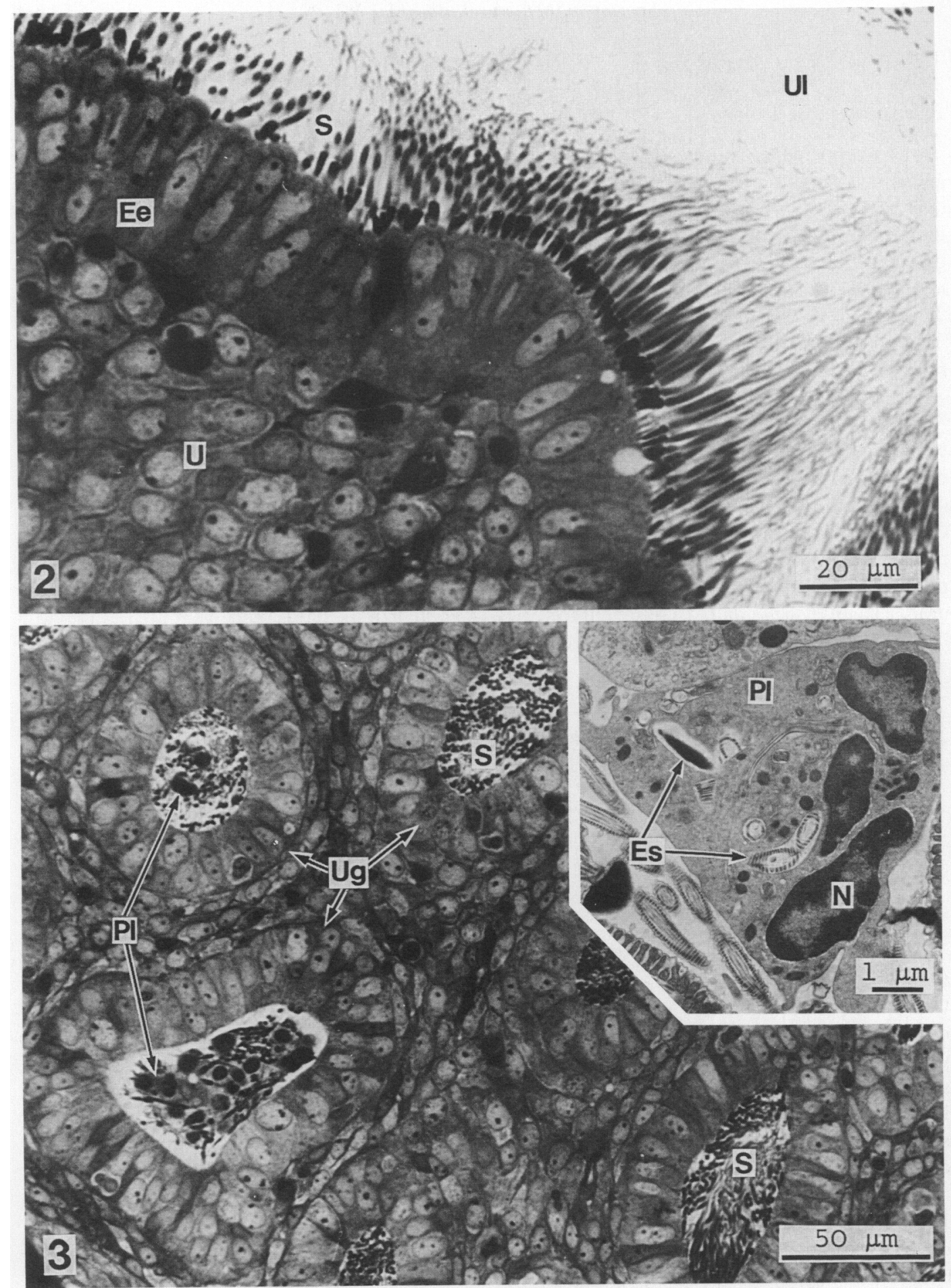

Fig. 2. Spermatozoa (S) lined up to the endometrial epithelial cells (Ee) in Bat 34. U, uterine wall; Ul, uterine lumen. Toluidine blue.

Fig. 3. Spermatozoa $(\mathrm{S})$ and polymorphunuclear leucocytes $(\mathrm{Pl})$ in the uterine glands $(\mathrm{Ug})$ of Bat 34. Toluidine blue. Inset: part of Fig. 3 at higher magnification showing a polymorphonuclear leucocyte $(\mathrm{Pl})$ containing engulfed spermatozoa (Es). N, nucleus. 


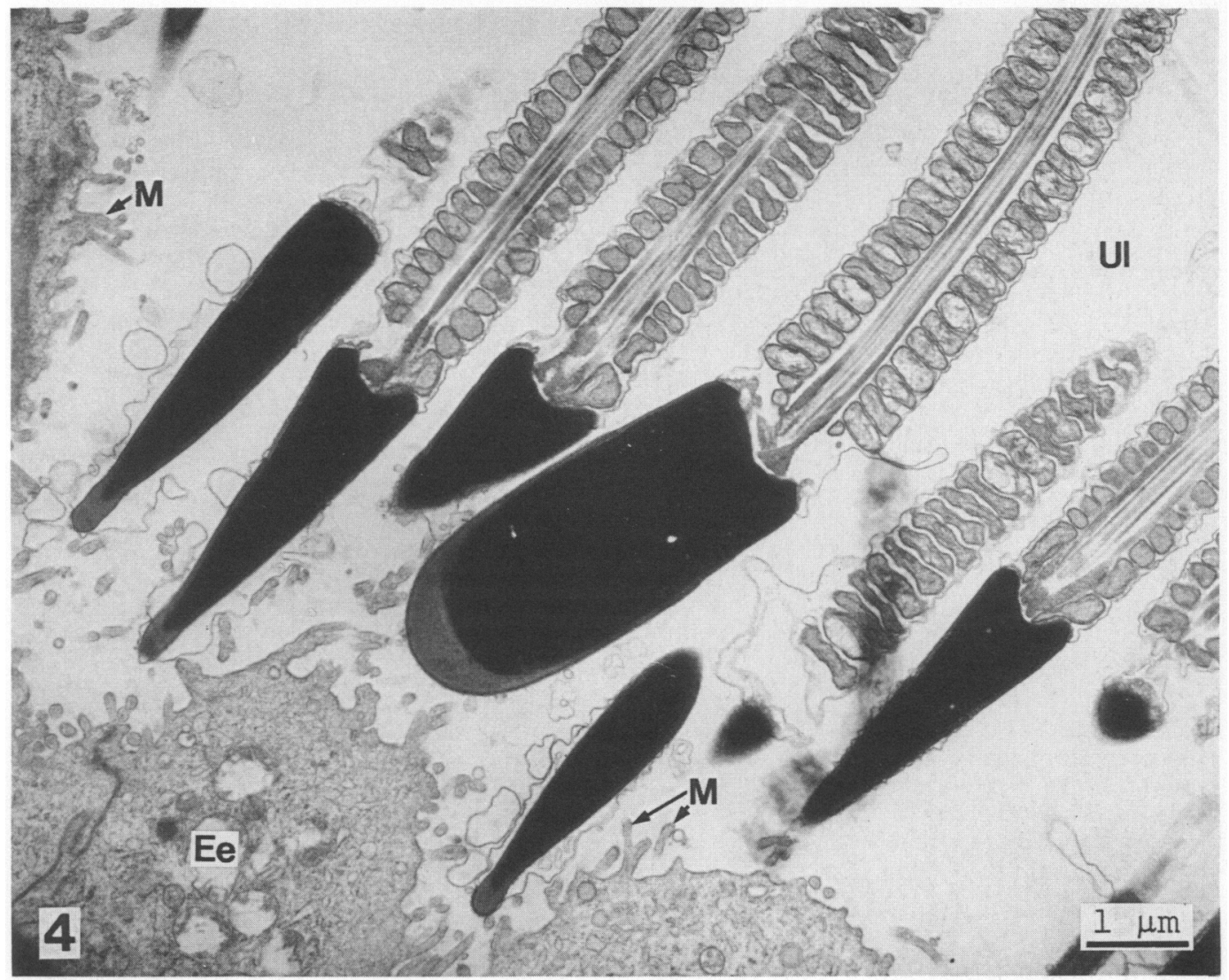

Fig. 4. Part of Fig. 2 at higher magnification showing spermatozoa in contact with microvilli (M) of the endometrial epithelial cells (Ee). Ul, uterine lumen.

Incidence of insemination. Smear and squash preparations of uteri examined by phase-contrast microscopy revealed that 4 of 10 bats ( 9 parous, 1 nulliparous) caught in a single Tuttle trap during the night of 19/20 August were inseminated. The following night when 2 traps enabled us to discriminate between bats entering and leaving the mine, no spermatozoa were found in squash preparations of the uteri of a sample of 10 parous females entering the mine. The following night, samples from both traps were examined. One female in a sample of 5 taken from each trap was inseminated. Overall a total of 6 of 30 bats caught at the mine entrance in the initial 2 days of this study was inseminated, but the reproductive tract of only 1 out of 15 females entering the mine contained spermatozoa.

During the next 2 weeks, 25 females were caught in the mine, 20 of which were in coitus (Table 1). Of the 16 females in which coitus was interrupted by capture, microscopy later revealed that 7 had not been inseminated. Similarly, the reproductive tracts of 3 females (Table 1, Nos 13, 19, 22) collected adjacent to copulating pairs were devoid of spermatozoa, as was the tract of a female (Table 1, No. 15) observed apparently soliciting a torpid male by pushing him with her muzzle. Twelve females were inseminated, 9 of which had been disturbed in coitus. Three females which were paired for at least 37,45 and 46 min gave no indication that they were aware of or disturbed by the observers. In 2 (Table 1 , Nos 11,12) the reproductive tract contained only few spermatozoa; in the other (Table 1, No. 34) spermatozoa were abundant. 

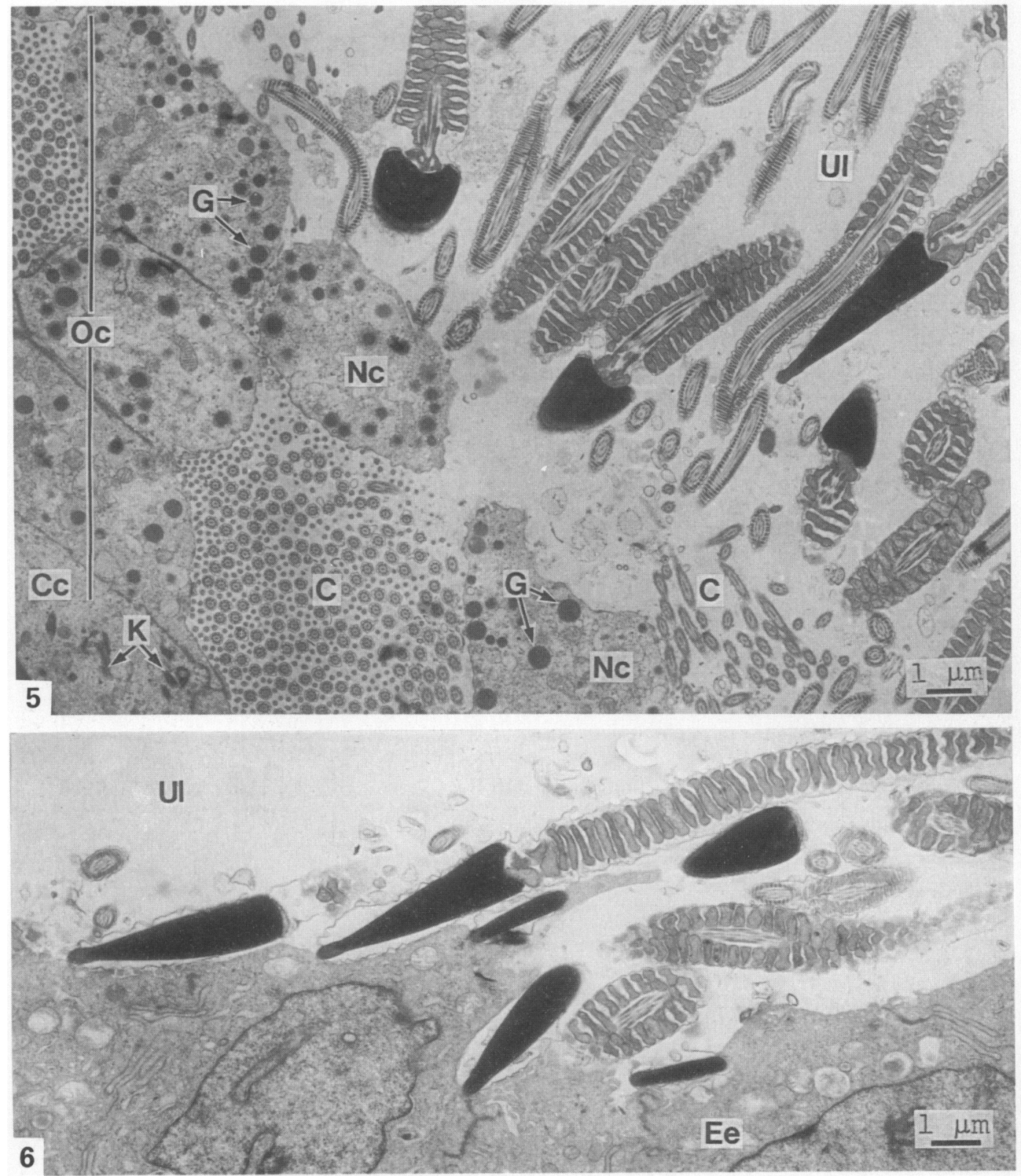

Fig. 5. Spermatozoa concentrating in the innermost recess of the uterine lumen (Ul) between the outer wall of the colliculus tubaricus $(\mathrm{Oc})$ and the endometrial epithelium facing it in Bat 14. $\mathrm{C}$, cilia; $\mathrm{Cc}$, ciliated epithelial cells; $\mathrm{G}$, granule; $\mathrm{K}$, kinetosome; $\mathrm{Nc}$, non-ciliated epithelial cell.

Fig. 6. Spermatozoa in oblique and vertical contact with the endometrial epithelial cells (Ee) of Bat 23. Ul, uterine lumen. 

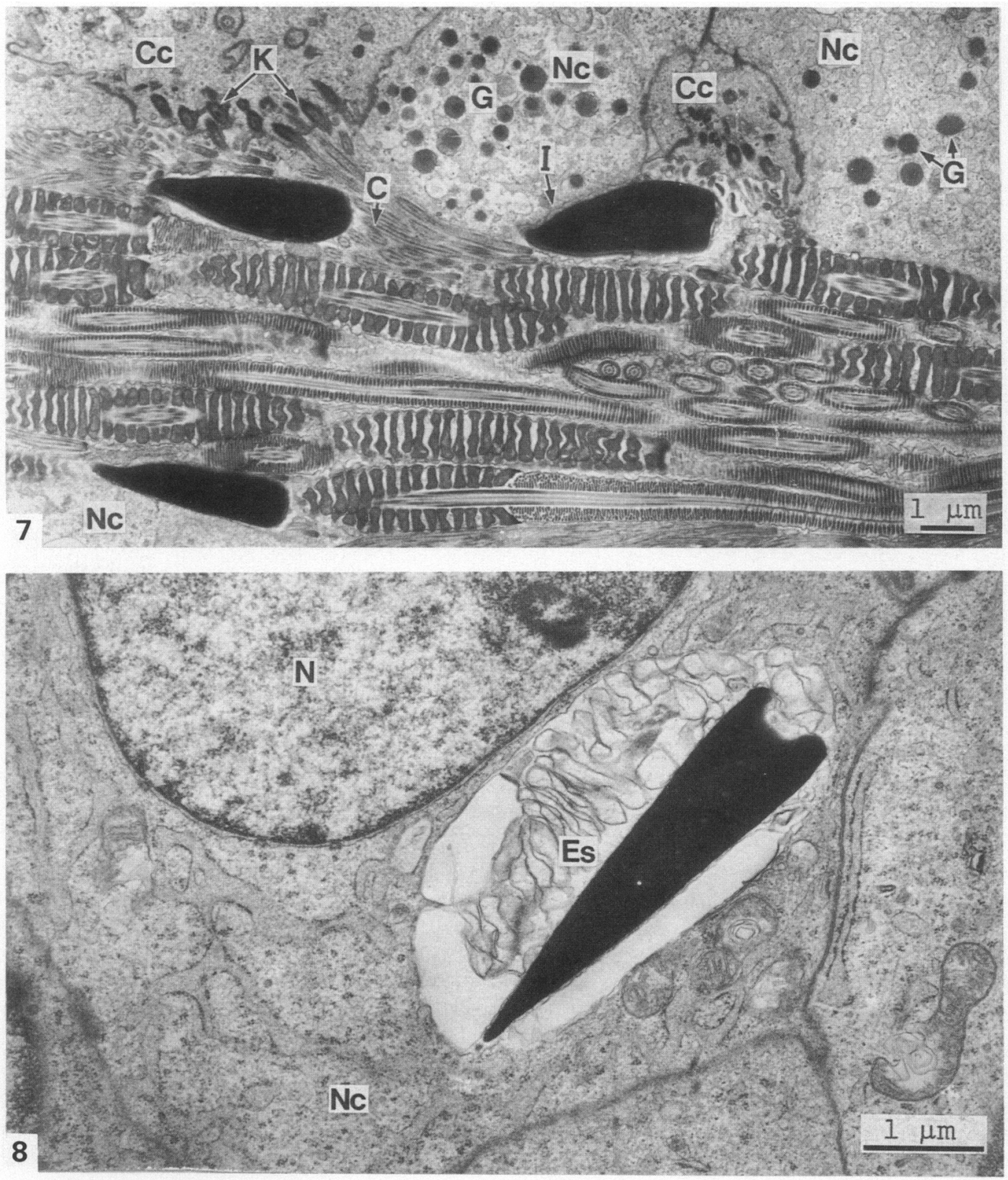

Fig. 7. Spermatozoa in close relationships with indentations (I) and/or the flat membrane of non-ciliated epithelial cells $(\mathrm{Nc})$ in the intra-mural part of the utero-tubal junction in Bat 34. The spermatozoa are surrounded also by cilia (C) of ciliated epithelial cells $(\mathrm{Cc})$. G, granule; $\mathrm{K}$, kinetosome.

Fig. 8. An engulfed spermatozoon (Es) within a non-ciliated epithelial cell (Nc) in the intramural part of the utero-tubal junction of Bat $34 . \mathrm{N}$, nucleus. 
Of the 3 specimens killed within 15 min of ceasing copulation (Table 1, Nos 23, 34), 2 had many spermatozoa in the uterus and the third (Table 1, No. 11-killed accidentally after an undisturbed copulation lasting $46 \mathrm{~min}$ ) had very few. In contrast, only one out of 9 inseminated females killed from 12 to $67 \mathrm{~h}$ after copulation contained large numbers of spermatozoa, in both the uterine lumen and the utero-tubal junction.

On 3 September, 10 bats were trapped at the mine entrance to provide a sample of the incidence of insemination at the end of the study. Spermatozoa were found in serial sections of the reproductive tract of only one of these females.

\section{Histological and ultrastructural observations}

In the asymmetric bicornuate uterus of the little brown bat the right horn is always slightly larger than the left. The utero-tubal junction is divided into the colliculus tubaricus which is a projection of the oviduct into the uterine lumen, and the intramural part which is the extreme caudal portion of the isthmus surrounded by the uterine wall (Fig. 1).

Spermatozoa in the uterus. When large numbers of spermatozoa were present in the uterine iumen (e.g. Table 1, No. 34), the endometrial epithelia were crowded with spermatozoa (Figs 1 and 2) and the uterine glands also contained many spermatozoa (Figs 1 and 3). Spermatozoa were orientated in parallel with and perpendicular to the epithelium, which is composed entirely of non-ciliated cells, and they were often in contact with the epithelial microvilli (Fig. 4).

When relatively small numbers of spermatozoa were present (e.g. Table 1, No. 20), almost all the spermatozoa were concentrated in the innermost recess of the uterine cavity between the outer wall of the colliculus tubaricus and the facing endometrial epithelium, with only a few spermatozoa in the uterine lumen proper. The epithelium overspreading the outer wall consists of both nonciliated granular cells and ciliated cells, and most of the spermatozoa in the recess established contact with either the epithelium covering the outer wall of the colliculus tubaricus (Fig. 5) or the endometrial epithelium. In the uterine lumen proper, the heads of some spermatozoa made oblique and vertical contact with the endometrial epithelium (Fig. 6).

Spermatozoa in the utero-tubal junction and caudal isthmus of the oviduct. Spermatozoa were found in the colliculus tubaricus in 10 of the 13 inseminated females and, in 9 of these, were also present in the intramural part of the utero-tubal junction in individuals killed from $10 \mathrm{~min}$ to $67 \mathrm{~h}$ after copulation was observed (Table 1). They were in close contact with indentations and/or the flat plasma membrane of the non-ciliated epithelial cells, although the spermatozoa were surrounded also by cilia of the ciliated cells (Fig. 7). Some of the epithelial cells in the intramural part had already engulfed spermatozoa (Fig. 8).

Sperm ascent into the caudal isthmus was rare. A few spermatozoa were found free in the lumen of this region in a single specimen (Table 1, No. 34) that contained the greatest number of spermatozoa throughout the reproductive tract.

Incidence of leucocytosis. Polymorphonuclear leucocytes were present in the uterine lumen and glands (Fig. 3) of all uteri examined irrespective of whether or not females had been inseminated. In inseminated females, there was no correlation between the incidence of leucocytes in the uterine lumen and glands and the interval between observed copulation and death (Table 1). Phagocytosis of spermatozoa occurred in some uterine glandular cavities (Fig. 3, inset) but was not evident in the uterine lumen. No leucocytes were recognized in the utero-tubal junction, except for a single specimen (Table 1, No. 3) in which spermatozoa were engulfed by leucocytes there.

\section{Discussion}

Observations during the present study that female little brown bats make copulation calls, while not precluding the possibility that males may do likewise, challenge the suggestion of Barclay \& 
Thomas (1979) that males appear to pacify struggling females with such calls. Males pinioned females with their wings and used their forearms to restrain females that were attempting to escape. Females appeared to elicit copulation from torpid males, and the fact that females collected adjacent to copulating pairs ('curious onlookers'-Fenton, 1984) were not inseminated suggests that they may have been awaiting their turn with the male, and supports the conclusion of Thomas et al. (1979) that mating in this species is promiscuous. The proportion of bats caught outside the mine that were inseminated did not increase throughout this study, which suggests that female bats may leave the area after they have been inseminated.

Undisturbed bats in drill-holes remained in coitus for up to $46 \mathrm{~min}$. The efficiency of the copulatory tie proposed by Wimsatt $\&$ Kallen (1952) from a study of the structure of the penis has been demonstrated, in that the power of flight was insufficient to break the tie. There are several reasons why such a mechanism may have evolved. A prolonged period of coitus may be necessary to stimulate ejaculation and sperm transport which would in itself minimize loss of spermatozoa. An alternative possibility is that ejaculation occurs at an early stage during copulation but that the bats remain in coitus after sperm transfer has taken place, and the long copulation may represent a period of mate-guarding by the male. Of the 16 females disturbed in coitus, 7 were not inseminated, and so on the present evidence either hypothesis is tenable. Female little brown bats may copulate with more than one male (Thomas et al., 1979) and multiple inseminations may therefore occur (Fenton, 1984). If sperm storage sites are limited, as seems likely from the excess spermatozoa in the uterine lumen in some individuals, then a male will maximize his chance of fertilizing a female by preventing other males from mating until sufficient time has passed for his spermatozoa to occupy the storage sites. We suggest that the long period of copulation, the efficient copulatory tie and the male holding fast to females attempting to disengage, are adaptations which prevent the female from leaving and other males from mating with her.

The fact that a small proportion of females caught at the mine entrance at the beginning of this study were already inseminated means that the bats observed copulating inside the mine may not have been doing so for the first time. However, copulation in little brown bats does not start until late August (Thomas et al., 1979) and the principal advance of the present study is to demonstrate that the intimate association between spermatozoa and the epithelial cells of the utero-tubal junction is established soon after insemination and very early during the 7-8 months of sperm storage. Our results also demonstrate that close relationships are established soon after insemination between spermatozoa and the uterine epithelium, where sperm heads make contact with epithelial microvilli as first described by Racey \& Potts (1970) for the pipistrelle bat (Pipistrellus pipistrellus). Krutzsch et al. (1982) were unable to find any comparable evidence that the uterus of the little brown bat was involved in sperm storage. Although the copulation to fixation interval in Table 1 cannot be regarded with certainty as the interval between first insemination and fixation, it shows a number of interesting features. In particular only a small proportion of females engaging in sexual activity in August had spermatozoa in their reproductive tracts, and high sperm numbers were not a consistent feature of those females in which copulation was apparently undisturbed.

The present study also shows that engulfment of spermatozoa by the epithelial cells of the utero-tubal junction and by polymorphonuclear leucocytes in the uterine glands was evident soon after insemination. Although these events were commonly observed by Krutzsch et al. (1982) after arousal from hibernation in spring, they were observed infrequently during the hibernation. Nevertheless, Krutzsch et al. (1982) hypothesized that the intimate association between stored spermatozoa and the utero-tubal epithelium might also be construed as a prelude to their destruction. However, the fact that the spermatozoa of little brown bats retain their fertility for prolonged periods of hibernation has been unequivocally established (Wimsatt, 1942, 1944). Special relationships between spermatozoa and female storage organs characterize all sperm-storing bat species so far investigated, suggesting that such relationships are an integral part of the mechanism of prolonged storage (Racey, 1979; Uchida \& Mōri, 1987). Mammalian semen in general contains defective spermatozoa incapable of fertilizing (Cohen, 1975) and in a species such as $M$. lucifugus which mates 
promiscuously (Thomas et al., 1979), the pool of spermatozoa for storage may be topped up as a result of additional inseminations. It is therefore advantageous to the female to remove spermatozoa which may be defective so that others can take their place in the spatially restricted storage sites. Although leucocytic infiltration and phagocytosis of spermatozoa by polymorphonuclear leucocytes they commonly observed in the uterus, they very rarely occurred in the utero-tubal junction, from which spermatozoa were removed by epithelial engulfment.

This study was supported by a grant from the National Science and Engineering Research Council of Canada to M.B.F. We also thank the Carnegie Trust for the Universities of Scotland, the University of Aberdeen and the Natural Environment Research Council who assisted with travelling and subsistence expenses for P.A.R. and M.I.A.

\section{References}

Barclay, R.M.R. \& Thomas, D.W. (1979) Copulation call of Myotis lucifugus: a discrete situation-specific communication signal. J. Mammal. 60, 632-634.

Barclay, R.M.R., Fenton, M.B. \& Thomas, D.W. (1979) Social behaviour of the little brown bat Myotis lucifugus. II. Vocal communication. Behav. Ecol. Sociobiol. 6, 137-146.

Cohen, J. (1975) Gametic diversity within an ejaculate. In The Functional Anatomy of the Spermatozoon, pp. 329-339. Ed. B. Afzelius. Pergamon, Oxford.

Fenton, M.B. (1970) Population studies of Myotis lucifugus (Chiroptera: Vespertilionidae) in Ontario. Life Sci. Contr. R. Ont. Mus. 77, 1-34.

Fenton, M.B. (1984) Sperm competition? The case of vespertilionid and rhinolophid bats. In Sperm Competition and the Evolution of Animal Mating Systems, pp. 573-587. Ed. D. Dewsbury. Academic Press, New York.

Krutzsch, P.H., Crichton, E.G. \& Nagle, R.B. (1982) Studies on prolonged spermatozoa survival in Chiroptera: a morphological examination of storage and clearance of intrauterine and cauda epididymal spermatozoa in the bats Myotis lucifugus and $M$. velifer. Am. J. Anat. 165, 421-434.

Racey, P.A. (1979) The prolonged storage and survival of spermatozoa in Chiroptera. J. Reprod. Fert. 56, $391-402$.

Racey, P.A. \& Potts, D.M. (1970) Relationship between stored spermatozoa and the uterine epithelium in the pipistrelle bat (Pipistrellus pipistrellus). J. Reprod. Fert. 22, 57-63.
Thomas, D.W., Fenton, M.B. \& Barclay, R.M.R. (1979) Social behaviour of the little brown bat Myotis lucifugus. I. Mating behaviour. Behav. Ecol Sociobiol. 6, 129-136.

Tuttle, M.D. (1974) An improved trap for bats. $J$. Mammal. 55, 475-477.

Uchida, T.A. \& Mōri, T. (1987) Prolonged survival of spermatozoa in hibernating bats. In Recent Advances in the Study of Bats, pp. 351-365. Eds M. B. Fenton, P. A. Racey \& J. M. V. Rayner. Cambridge University Press, Cambridge.

Wim.satt, W.A. (1942) Survival of spermatozoa in the female reproductive tract of the bat. Anat. Rec. 83, 299-307.

Wimsatt, W.A. (1944) Further studies on the survival of spermatozoa in the female reproductive tract of the bat. Anat. Rec. 88, 193-204.

Wimsatt, W.A. (1969) Some interrelations of reproduction and hibernation in mammals. Symp. Soc. exp. Biol. 23, 511-549.

Wimsatt, W.A. \& Kallen, F.C. (1952) Anatomy and histophysiology of the penis of a vespertilionid bat, Myotis lucifugus, with particular reference to its vascular organization. J. Morph. 90, 415 466.

Wimsatt, W.A., Krutzsch, P.H. \& Napolitano, L. (1966) Studies on sperm survival mechanisms in the female reproductive tract of hibernating bats. I. Cytology and ultrastructure of intrauterine spermatozoa in Myotis lucifugus. Am. J. Anat. 119, 25-60.

Received 23 September 1986 